\title{
Hydrogeology Journal Reorganization and Publication Policy on Originality
}

Received: 15 July 2005 / Accepted: 15 July 2005 / Published online: 5 August 2005

(C) Springer-Verlag 2005

\section{Curing Hydrogeology JournaPs Growing Pains}

Paradoxically, in part due to Hydrogeology Journal's growing popularity as a preferred publication outlet, our journal has encountered several obstacles in the past months resulting in delays in various stages of review and publication. These include overly lengthy times before completion of some initial manuscript reviews and delays in creation of proofs and online appearance of published articles. A further dilemma has been the one-year wait in printing most articles following acceptance and online publication, as described in a recent Editor's Message (issue 12(6) 2004), wherein opinions of authors and readers concerning possible solutions were sought. Several circumstances had underlain these delays: a significant increase in both the number of articles submitted and accepted for publication, too small and overly busy $H J$ Editorial staff (especially the Executive Editor!), and reorganization of our publisher's staff and procedures.

Significant steps have now been taken by IAH and the Executive Editor to alleviate these difficulties. $H J$ will appear more frequently and with many more printed pages each year. Our staff procedures and roles, which had evolved from the time the journal was new and small, are being reorganized and new staff has already begun to work for $H J$. These changes are described below. Some changes are still taking place at Springer Verlag that impact all journals they publish, and their consequences will take some more time to evaluate.

\section{Re-organization and Staff Changes}

$H J$ organization and staffing are changing. Our Managing Editors, Perry Olcott and Robert Schneider, coincidentally ended their terms this year providing an opportune time for a more wide-ranging reorganization than may have otherwise occurred. Perry (since 2002) and Bob (since 2001)

Clifford I. Voss, Executive Editor made great efforts for $H J$ and its authors, and we much appreciate their dedication, persistence and care over the past several years. Their role as Managing Editor (ME) was to make publication decisions on reviewed manuscripts, and they interacted with authors throughout the process of revising manuscripts. As MEs, they also had responsibility for scientific language and format editing, helping authors to achieve clear scientific expression and consistency with $H J$ scientific format.

In our reorganization, the ME role has changed and we will have three new MEs. The new MEs will carry out an initial review of newly submitted manuscripts and will assign these to Associate Editors (we have over 60 AEs) for technical review. The initial review and assignment to AEs was a job previously done by the Executive Editor. Upon completion of reviews, the MEs will make publication decisions on reviewed manuscripts, interacting with authors throughout the process of revising manuscripts, as in the old ME role. MEs will give technical acceptance to manuscripts for publication. The new MEs will not carry out scientific language and format editing as before. Instead, IAH has hired a new Technical Editorial Assistant (TEA) to carry out this task following technical acceptance of each manuscript. This is a new role in $H J$ staff. After scientific editing and final acceptance of each manuscript by the TEA, copy editors at Springer will carry out the final editing required for publication, as they have done previously.

Our Editorial Office manager (EO), Christine Watson, has begun other duties in the IAH office and IAH has hired a new EO. Christine has been an invaluable resource in managing journal business since 2002. We are grateful that she will still be available to give $H J$ staff advice and support.

Our new staff is enthusiastic and we intend to serve $H J$ authors and readers to the best of our ability. The new $H J$ staff organization is as follows:

Executive Editor:

Clifford I. Voss

Managing Editors:

William W. Dudley

Bridget Scanlon 
Maria-Theresia Schafmeister

Craig Simmons

Technical Editorial Assistant: Sue Duncan

\section{Editorial Office Manager:}

Catherine O'Flynn

Managing Editor, William Dudley, is supporting our transition to the new organization throughout 2005. Bill holds a BSE in Geological Engineering from Princeton University (1960) and a PhD in Geology from the University of Illinois (1967). Following two years in the US Army Corps of Engineers conducting hydrogeologic studies related to the Plowshare program (peaceful uses of nuclear explosives), he began a 36-year career of hydrogeologic studies and management positions in the US Geological Survey (USGS). His investigations experience has included regional flow analysis of hard-rock terrains, geophysical definition of aquifer systems, well-field effects on endangered-species habitats, deep-well testing, and analysis of regional hydrogeologic issues related to underground nuclear-explosives testing and disposal of high-level radioactive waste. In the USGS, he also served as District Chief for water-resources investigations in the state of Wyoming (USA) and as a Branch Chief and science advisor for USGS site-characterization studies of the proposed nuclear-waste disposal site at Yucca Mountain, Nevada (USA).

Managing Editor, Bridget Scanlon studied Geology first at Trinity College, Dublin, Ireland, receiving her BS in 1980, then at the University of Alabama, USA, receiving her MS in 1983. She received her PhD in Geology from the University of Kentucky, USA, in 1985, for study of chemical, physical, and microbiological characteristics of groundwater in Kentucky. Bridget worked at the Geological Survey of Ireland, and with private consulting companies, as well as at the above universities, before moving to $\mathrm{Bu}-$ reau of Economic Geology at The University of Texas at Austin, USA, in 1987. Since 1999, she has been a Senior Research Scientist at the Bureau of Economic Geology. Her main research interests concern evaluation of the impact of climate variability and land use change on groundwater recharge, application of numerical models for simulating variably saturated flow and transport, use of soil physics and environmental tracers to quantify water and solute fluxes in the unsaturated zone, and controls on nitrate contamination in aquifers. She is the recipient of several distinguished awards and a member or chair of several active committees, including the USA National Science Foundation's Consortium of Universities for the Advancement of Hydrologic Sciences (CUAHSI) Prototype Long-term Hydrologic Observatory (LTHO) Design Team, and Proposed Texas Hydrologic Observatory. Bridget was the Guest Editor (with Peter Cook) of the 2002 theme issue of $H J$ on 'Groundwater Recharge'; and served as an Associate Editor of $H J$ for four years.

Managing Editor, Maria Schafmeister studied Geology and Palaeontology at the University of Kiel and the Free University of Berlin receiving her Diploma (1984) and $\mathrm{PhD}$ at Free University of Berlin (1989). Her projects in- volved study of groundwater flow and transport modelling, pesticide transport, field-tracer tests, and evaluation of groundwater contamination by means of multivariate and geostatistical analyses. Maria worked at Université Laval in Québec Canada and at the Free University of Berlin in Hydrogeology and Mathematical Geology. Since 1998, she has been the Chair in Applied Geology and Hydrogeology at the University of Greifswald, Germany. More recently Maria has become head of the Joint Graduate Education Program (JGEP) between Hanoi University of Sciences in Vietnam and the University of Greifswald. Her main research interests concern use of quantitative and geostatistical measures in hydrogeological investigations and predictions. Maria served as an Associate Editor of $H J$ for four years.

Managing Editor, Craig Simmons received his $\mathrm{PhD}$ at Flinders University, Australia (1997) for study of environmental effects of saline disposal basins. His main interest involves study of variable-density groundwater flow phenomena. His work utilizes a range of field-based, modeling and laboratory based approaches with applications to salinity, saline disposal basins and salt lake hydrology, fractured rock hydrology, catchment scale hydrogeology and benchmarking groundwater flow and solute transport models. Craig has worked at CSIRO (Commonwealth Scientific and Industrial Research Organization) in Australia, at the USGS and The University of Texas at Austin in the USA. Craig served as Manager of Australia's Centre for Groundwater Studies from 2000 to 2002 . He is currently the Research and Academic Coordinator for the Centre for Groundwater Studies, and an Associate Professor in Hydrogeology at Flinders University in Adelaide. In 2002, Craig was awarded the national Australian Award for University Teaching (Physical Sciences and Related Studies) and in 2005 he was awarded the prestigious Tall Poppy Award which recognized him as an outstanding research scientist in Australia. Craig previously served as Associate Editor of Water Resources Research and Ground Water and as an Associate Editor of $H J$ for four years.

Technical Editorial Assistant, Sue Duncan has nearly 20 years of experience in UK groundwater research, regulation and consultancy, and has been an IAH member since 1995. She attained a First Class degree in Environmental Science from the University of Plymouth, followed by several years with the Water Research Centre (WRC), in the UK and in Italy. As Senior Scientist with the Environment Agency, she was involved in the development of the national groundwater quality monitoring programme, particularly with respect to nitrate and pesticides. In this work she is most likely to be remembered as Sue Hennings. More recently, Sue has moved into the field of scientific editing.

Editorial Office Manager, Catherine O'Flynn is based in Birmingham, UK. She has previously worked in web design publishing and has spent the last two years teaching English in Catalunya, Spain, and working with language students online. Catherine is the coordinator of all activities associated with $H J$. She aids in communications among $H J$ staff, Associate Editors, reviewers and authors, and manages our online manuscript submittal and 
tracking system, Manuscript Central. Catherine tracks the processing of each manuscript. All questions concerning publishing in $H J$ should initially be directed to Catherine at coflynn@iah.org.

\section{Increased Size and Frequency}

The number of printed pages in each $H J$ volume has grown gradually over the past years. However, in response to the ever-growing number of articles submitted and accepted, the page count will increase significantly beginning with the next volume. The current volume, 13, has 800 pages; subsequent volumes will be $75 \%$ larger. Beginning with volume $14, H J$ will have 1400 pages each year. This will allow the printing backlog of accepted articles to be eliminated. In order to hurry the reduction in backlog, issues 13(5) and 13(6) will appear as a double issue at the time 13(5) normally appears this year. Then, issues 14(1) and 14(2) will appear as a double issue when 13(6) would have appeared. Altogether this schedule moves more printed pages into the 2005 publishing year. The 2006 theme issue is planned for appearance as 14(3), early in 2006. Beginning with volume $14, H J$ will appear in 8 issues each volume (increased from 6 ), with one issue of $H J$ to be distributed approximately each 6 weeks. Note that this higher frequency will begin only in 2007 (volume 15), because only the latter 6 issues of 14 will appear in 2006. The increased size and frequency of $H J$ is a greatly increased benefit to readers, authors and IAH members.

\section{Changes to the Review Process}

We have had considerable difficulty in obtaining timely reviews from some Associate Editors (AEs) and reviewers. This has two negative impacts: 1- significant delays for initial publication decisions causing justifiable author concern, and 2- a great deal of extra work for the $H J$ staff in tracking and prodding delinquent AEs and reviewers. When AEs agree to join the $H J$ Editorial Board, they make a commitment to manage the review process promptly, providing their recommendation concerning publication on time, or when not possible, to communicate their schedule to $H J$ staff. AEs also need to respond promptly to initial review requests and other contacts. Much time can pass while $H J$ staff waits for AE responses, delaying the publication decision. The Executive Editor has not always been able to track and prod delinquent AEs, regretfully resulting in some severely delayed reviews. In turn, the AEs must track and prod delinquent reviewers in order to be able to return the completed review package to $H J$ staff on time. (A reviewer who agrees to review an article also makes a commitment to complete the task in the agreed timeframe.) Furthermore, some AEs have delayed initiation of assigning reviewers until the maximum allotted time for review and if another $\mathrm{AE}$ must be appointed, then the review process can take twice as long as intended or longer. Regretfully, this has happened several times in the past year. The large majority of AEs have been quite conscientious through the years, while the few who need significant prodding have caused major delays in processing of some manuscripts and much anguish for authors and $H J$ staff. We will be more vigilant in addressing these problems and will take appropriate action to sustain review schedules and to obtain clear commitments from AEs when they agree to join the Editorial Board.

As a further experiment intended to speed the review process, the time allotted for each step will be reduced, with the aim that a first publication decision should be returned to the author 3 to 4 months after submittal. Furthermore, AEs are now asked to assign and obtain 3 (rather than the previous 2) reviewers. We prefer to receive 3 completed reviews within the allotted time, but if only 2 are obtained on time, then a publication decision will be made without the third review. The Managing Editors will track the progress of AEs that they assign for manuscript review. It is expected that, over the next year, these steps will significantly shorten the time between submittal and initial publication decision. In the future, these procedures may be adjusted as necessary to improve the review process.

\section{Hydrogeology Journal Policy on Publication Originality}

The Erratum appearing in this issue of $H J$ brings to the fore sensitive questions that all authors must face when reusing previously published material in a new publication. A brief discussion here is intended to highlight some guidelines and principles for publication in $H J$.

When a manuscript is submitted to $H J$, the author must guarantee that it has not been published previously, in whole or in part. Only manuscripts that are predominantly original may appear in $H J$. A possible exception concerns manuscripts that have appeared in 'grey literature' such as conference proceedings or in-house or local technical documents that are not widely accessible. Such a manuscript should be declared as having appeared previously when the author submits, and it may be considered as original and publishable in $H J$ on a case-by-case basis to be decided by the Editors. When submitting online, the author is always asked: "Have any parts of the manuscript been published previously? If so, please explain how this manuscript is original." This question must be carefully considered by each author and information concerning previous (or possible simultaneous) publication of any parts of the manuscript must be given.

A journal's technical review process attempts to confirm the originality of ideas and information presented in a submitted article. The efficacy of this check depends on the extent of detailed reviewer knowledge, which often cannot be expected to suffice. Thus, it is the responsibility of the author to completely and honestly characterize previously published material contained in a submitted article. If unreferenced duplication is later discovered in a published $H J$ article, public notice must be given about the incident.

Submitting the same or similar manuscripts (even when both present similar original material) to more than one 
journal at the same time also violates the requirement of originality, should more than one of the manuscripts be accepted and published. Furthermore, authors should not make such duplicate submittals to increase their chance of achieving publication, with the intent of withdrawing one manuscript should more than one be accepted, as this wastes review efforts by the journals and may be considered as unethical behavior.

All material, including text, figures and tables, that has been published in a journal is normally subject to a legal copyright. This means that the author may not use previously published material without express permission from the original publisher - even if the material comes from the author's own published article. Authors must obtain permission and also must, in the new article, make clear reference to the original publication for each item reproduced. Many authors are not attentive to the necessity of obtaining such permission.

Submitting a manuscript that does not differ substantially from a previously published manuscript, and proclaiming it as an original contribution may be considered both a case of copyright violation and of self-plagiarism. This is also a disservice to the scientific community, though it may abet self-promotion. Publishing similar articles in peer-reviewed journals needlessly increases costs of journal production and diminishes the scientific impact of articles and the journals in which they appear. This is a practice that must cease. 